\title{
Using mobile phones and social media to facilitate education and support for rural-based midwives in South Africa
}

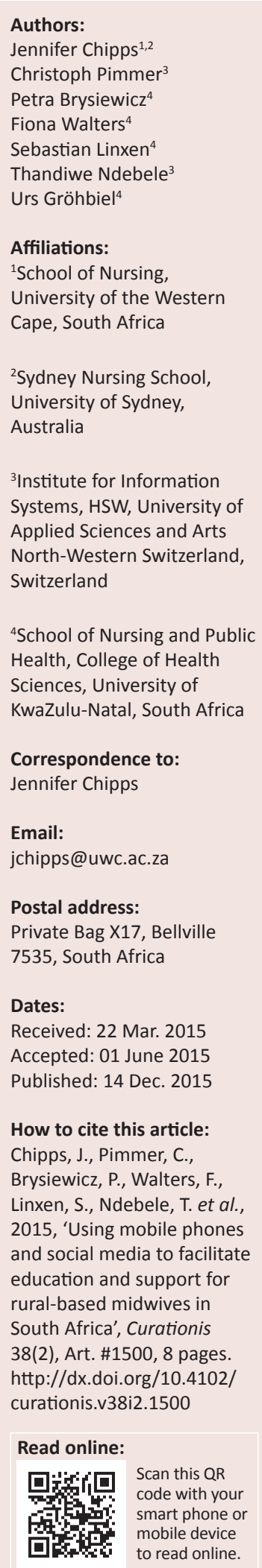

Authors:

ennifer Chipps

Thandiwe Ndebele

University of the Western

${ }^{2}$ Sydney Nursing School,

University of Sydney,

Applied Sciences and Arts

North-Western Switzerland,

${ }^{4} \mathrm{~S} c h o o l$ of Nursing and Public Health, College of Health

Sciences, University of

KwaZulu-Natal, South Africa

Correspondence to:

Email:

Private Bag X17, Bellville

Dates:

Accepted: 01 June 2015

Linxen, $S$, Ndebele, T. et al.,

2015, 'Using mobile phones and social media to facilitate rural-based midwives in South Africa', Curationis

38(2), Art. \#1500, 8 pages.

http://dx.doi.org/10.4102/

Read online:
Background: Empirical studies show the value of mobile phones as effective educational tools to support learning in the nursing profession, predominantly in high income countries.

Problem statement: The rapidly increasing prevalence of mobile phone technology in Africa nourishes hopes that these tools could be equally effective in lowly resourced contexts, specifically in efforts to achieve the health-related Millennium Development goals. The purpose of this study was to investigate the perception and use of mobile phones as educational and professional tools by nurses in lowly resourced settings.

Methodology: A quantitative survey using self-administered questionnaires was conducted of rural advanced midwives.

Results: Fifty-six nurses (49.6\%) from the 113 rural-based midwives attending an advanced midwifery training programme at the University of KwaZulu-Natal, South Africa, filled in a questionnaire. The results showed that, whilst nurses regarded their technology competences as low and although they received very little official support from their educational and professional institutions, the majority frequently used mobile functions and applications to support their work and learning processes. They perceived mobile devices with their voice, text, and email functions as important tools for the educational and professional activities of searching for information and engaging with facilitators and peers from work and study contexts. To a lesser extent, the use of social networks, such as WhatsApp and Facebook, were also reported.

Conclusion and recommendation: It is concluded that educational institutions should support the appropriate use of mobile phones more systematically; particularly in relation to the development of mobile network literacy skills.

\section{Introduction}

As part of a strategy to address three of the Millennium Development goals to improve child and maternal health and fighting HIV, rural-based registered midwives have been enrolled in a part-time, two-year, Advanced Midwifery Programme at the University of KwaZulu-Natal, South Africa.

\section{Background and selective literature review Challenges of health workers in rural areas and the potential of mobile technology}

In rural and disadvantaged areas in lower- and middle-income countries, health workers have limited access to education, up-to-date knowledge, and professional networks. These conditions contribute, amongst others, to professional isolation, attrition, poor performance, and emigration (HIFA Report 2010; Hongoro \& McPake 2004; WHO 2010). In these settings the mobile phone is often the most reliable technology for health care providers to perform their work (Crow et al. 2012). In fact, in low- and middle-income countries, the use of mobile phones has dramatically increased and is considered to have a large impact on developmental issues. In South Africa this increase includes 94.2 mobile cellular subscriptions per 100 people (The World Bank 2011) and a mobile broadband penetration that had reached $29 \%$ by the end of 2013 (ITU 2014).

In this light, United Nations organisations, such as UNICEF, ITU and the World Bank, have great expectations for the potential of mobile phones to support and educate health care 
providers (Holmes 2010; ITU 2010; The World Bank 2012), and educational institutions have started piloting these tools (Chang et al. 2011).

\section{Mobile learning and communication}

Mobile phones, similar to the old digital assistants, form new kinds of communication and interaction that can also define novel approaches to teaching and learning (De Marcos Ortega et al. 2011; McLeod \& Mays 2008). In nursing education and midwifery, smartphones can be used for quick access to educational materials and guidelines during clinical and class activities or clinical conferences; a range of applications expand the smartphone functions even further (Havelka 2011; Phillippi \& Wyatt 2011). In a number of studies, mobile phones are reported to be used for educational purposes in clinical contexts to access learning materials (Clay 2011) or social support at the bedside (Young et al. 2010). However, some barriers to the use of mobile phones in nursing have been recorded, including cost, disease transmission, equipment interference (Phillippi \& Wyatt 2011), and ethical issues of data security.

However, despite the increasing pentetration of mobile devices in low- and middle-income countries, mobile learning research seems to focus on learning at schools, universities, workplaces, or on life-long learning in high income areas (Hwang \& Tsai 2011; Wu et al. 2012). There is still little solid knowledge available about how to use mobile media to effectively support health workers in disadvantaged areas in low- and middle-income countries (Braun et al. 2013; Deglise, Suggs \& Odermatt 2012; Mechael et al. 2010; Tomlinson et al. 2013). In these settings, Traxler and Kukulska-Hulme (2005) consider the potential of mobile learning to provide education without dependence on extensive traditional communications infrastructure. However, it is argued that current perceptions about mobile learning and development seems to be oversimplified and techno-centred (Traxler 2012; Winters 2013). Similarly, most health studies focus on smallscale pilot interventions, adopt a 'techno-optimistic' view, do not pay attention to socio-cultural practices and have a limited theoretical foundation. Beyond interventions, published literature on the gradual growth and appropriation of mobile phones for health and educational purposes is scarce (Chib 2013; Chib, Van Velthoven \& Car 2014).

Midwifery studies in Indonesia point to the potential of cell phones. Their use is positively associated with access to institutional resources (Lee, Chib \& Kim 2011), their capacity to solve patient-related challenges, the enhancement of peer interaction (Chib \& Chen 2011), the empowerment and respect that midwives enjoy within their communities (Chib \& Chen 2011), and higher levels of health knowledge (Lee et al. 2011). These positive outcomes have been realised in a non-linear approach resulting from the dialectical tensions amongst the interactions of benefits and constraints, such as gender or midwifery roles, a lack of technical competency and resource control in traditional social hierarchies (Chib \& Chen 2011).

\section{The use of mobile technology to access social media and social networks}

Internet-enabled mobile phones increasingly permit users to access social network sites. Indeed, statistics allow the conclusion that smart mobile phone users spend considerably more time on social media and social network sites than users of personal computers (Favell 2010). Again, medical and health research has concentrated on the educational use of social media in high income countries (Gray, Annabell \& Kennedy 2010). Their findings identify educational benefits as well as risks regarding ethical issues and privacy. However, very little research has been conducted about the use of social software on mobile phones in developing or transitional countries, though their potential is considered to be high (Kolko, Rose \& Johnson 2007). Only a few studies have analysed the rich educational potential of the convergence of mobile phones and social networking sites for nursing and medical education in developing countries. A study, for example, illustrates how Asian health professionals are using social network sites on their mobile phones to deliberately engage with explicit forms of educational content, such as quizzes and case presentations, as well as to participate in virtual professional communities that allow for the announcement and negotiation of occupational status and professional identities. Such technologies permit the users' educational engagement beyond local communities and facilitate loose and ephemeral connections to professional (health) networks (Pimmer, Linxen \& Gröhbiel 2012a; Pimmer et al. 2013). A qualitative study in a similar programme setting as this investigation concluded that midwives are using their mobile phones to support authentic problem solving in relation to critical patient cases to facilitate reflective practice and to establish social presence in the form of emotional support and inclusion (Pimmer et al. 2014). As a result of the prevailing qualitative findings it can be concluded that future research must concentrate more attention on analysing such applications. Further research is required to address the extent to which the engagement with such technologies impacts learning and communicating health information.

\section{Problem statement}

More than 100 midwives enrolled in a two-year Advanced Midwifery Programme at five rural sites in the KwaZuluNatal Province of South Africa. The challenge for the teaching staff of the programme was to connect these midwives to the university in real time and to ensure that they had ready access to all learning materials and resources. Though lectures were provided by means of videoconferencing and midwives reported that they had access to computers, it was clear that uptake of the learning management systems had been low (Chipps et al. 2015). A previous study concluded that, despite the high possibility of phone ownership (Pimmer et al. 2014), it was not clear what the use for, and perceptions about, the functionality of mobile phones for educational and work-related activities had been. 


\section{Definition of key concepts}

ICTs: ICTs are information and communication technologies that include hardware, such as computers (desktop and laptop) and mobile phones (smartphones and traditional mobile phones), as well as software applications and communication functions, such as calling and messaging.

Mobile phones: A subset of ICTs includes smartphones (e.g. iPhone, Blackberry) that have additional functions to basic phoning and SMS (text messaging), such as Internet access and a range of applications, and mobile phones without Internet access.

Facilitators: Facilitators were Registered Educators and Midwives employed by the university to support students clinically and academically in rural areas.

\section{Research objectives of the study}

The research objectives were to establish existing usage patterns and perceptions of ICT and, in particular, of mobile phones and social media and networks, e.g. Facebook to gain a better understanding for the purpose of incorporating these technologies into existing educational programmes.

\section{Research method and design Context of the study}

The context of the study was the Advanced Midwifery Training Programme at the University of KwaZulu-Natal, South Africa, which was presented at five remote rural hospital sites and one university site. Because the midwifery students were living, working, and studying locally a blended educational programme had been designed to address their educational needs with the aim of not removing them from their local setting for educational purposes. That included weekly in-person videoconferencing lectures from the university to the local rural hospitals and the appointment of local facilitators to support the midwives at those rural sites. Programme material in four subjects had also been placed online by utilising an open source learning management system; however, most of the material and resources were photocopied and posted to the rural sites.

\section{Design}

A quantitative survey on the use and effectiveness of mobile phones, computers and social networks for work and educational purposes was conducted in the second half of 2012 by means of a structured questionnaire. This survey was the second component of a mixed method study to investigate mobile phone and social media usage for educational purposes in lowly resourced settings (Pimmer et al. 2014).

\section{Sample and population}

The population of the study comprised 113 advanced midwifery nursing students enrolled in the two-year
TABLE 1: Respondents of the study.

\begin{tabular}{lcc}
\hline Site & Couse respondents & Sample (\%) \\
\hline Site A & 13 & $13(100)$ \\
Site B & 17 & $13(76.5)$ \\
Site C & 12 & $5(41.7)$ \\
Site D & 20 & $11(55.0)$ \\
University site & 51 & $14(27.5)$ \\
\hline Total & $\mathbf{1 1 3}$ & $\mathbf{5 6 ( 4 9 . 6 )}$ \\
\hline
\end{tabular}

programme at the time of the survey; 69 respondents were second year students whilst 44 of them were first year students. No sampling was done and all midwives were eligible to participate in the study, resulting in 56 valid respondents ( $49.6 \%$ response rate): 45 from the second year $(65.2 \%)$ and 11 from the first year (25.0\%). Participation varied across sites, ranging from $100 \%$ at one rural site to $27.5 \%$ at the university attendance site (Table 1 ).

\section{Materials}

The questionnaire was developed and refined based on the findings of previous qualitative studies, mainly from an interview-based investigation from the same programme setting (Pimmer et al. 2014) and, additionally, from a qualitative study from a different low resourced context (Pimmer, Linxen \& Gröhbiel 2012b). In addition, items were adopted from an extensive survey with established validity and reliability that had examined the use and perception of information technology by undergraduate students (EDUCAUSE 2011). The questionnaire was in English and took approximately 20 to 30 minutes to complete.

\section{Data collection and analysis methods}

The questionnaires were distributed by the local facilitators and then returned to the research staff at the university. Data were entered in the SPSS version 22.0 computer program and analysed using appropriate descriptive and non-parametric statistics. Frequency of mobile phone usage was estimated out of a possible 365 days a year, with responses assigned the following estimated values to convert frequency of use to a numeric variable: 'using it more than once a day' $=356$, 'more than once a week' $=208$ (52 weeks $x 4$ times a week), 'more than once a month' $=48$ (12 months x 4 times a month), and 'once a month' $=12$. Four times was taken as an estimate of use per week or month. Inapplicable data were excluded and missing data were included.

\section{Ethics}

The study received ethical clearance from the Human and Social Science Ethics Committee from the University of KwaZulu-Natal and permission was granted by the School of Nursing at the university to conduct the study. Written informed consent was obtained, anonymity of respondents was maintained and participation in the study was voluntary. Data were not able to be traced back to the respondent. 


\section{Results \\ Description of sample}

Fifty-six midwives (49.6\%) from four rural sites and one site attached to a university responded to the survey (Table 1); 42 from the second year of training (60.9\%) and 11 from the first year of training (25.0\%). Of the 56 respondents, only two midwives reported that they were male. The average age was 42.5 years (SD 75) with a range between 30 and 57 years. Only six respondents (10.7\%) reported having completed a degree in nursing with the rest having completed diplomas in nursing.

\section{General mobile phone use}

Though respondents in this study did report having access to computers ( $n=48 ; 85.7 \%$ ), nearly a quarter of them $(n=13 ; 23.2 \%)$ had no computer access at home. In contrast, all respondents excepting two (96.4\%) reported owning a mobile phone. Twenty-eight $(50.0 \%)$ of the respondents reported owning a smartphone. The mobile phone was used most frequently for making phone calls with an estimated average use of 302 days a year (SD 108.9); 41 respondents $(73.2 \%)$ reported that they made phone calls several times a day. That was followed by SMSs or texting with an estimated use of 250 days a year (SD 135.8). Twenty-nine (51.8\%) respondents reported that they sent text messages several times a day; respondents reported sending an average of 4.7 (SD 5.2, median 3, range 0-27) outgoing messages per day and receiving an average of 6.2 (SD 6.4, median 5, range 0-30) messages per day. The WhatsApp messaging application had a general estimated use of 181.8 days a year (167.4) and was used several times a day by 13 (23.2\%) respondents; Facebook was used for 127.9.8 days a year (143.8) and was used several times a day by 6 respondents (10.7\%); email had an overall general estimated use of 101.6 days a year (143.5) and was used several times a day by 7 respondents (12.5\%). There were significant differences by age group for how often they used Facebook functionalities, with only one of the 9 respondents over 50 years old reporting using Facebook at all and then only about once per month $\left(X^{2}=20.1\right.$ [df $\left.=8\right]$, $p=.002$ ).

\section{Current use of mobile phones and social networks to support learning}

Mobile phones: When examining how mobile phones were used to support learning, three areas were identified: (1) contacting facilitators or peers to discuss topics and tasks from the course, (2) contacting facilitators or peers to discuss work-related topics and tasks, and (3) searching for information and using mobile phones in the clinical context.

Forty-five $(80.4 \%)$ respondents thought mobile phones were important for contacting programme facilitators, 38 (67.9\%) for contacting colleagues, and 40 (71.4\%) for contacting their peers or fellow students. The majority of the respondents ( $n=47 ; 83.9 \%)$ thought they were important for searching for work-related information, whilst $40(71.4 \%)$ respondents
TABLE 2: Mobile phone functionalities used $(N=56)$.

\begin{tabular}{lcclccc}
\hline Variable & \multicolumn{2}{c}{ Programme related } & & \multicolumn{3}{c}{ Work-related } \\
\cline { 2 - 3 } \cline { 7 - 8 } & $\begin{array}{c}\text { Facilitators } \\
(\mathbf{\%})\end{array}$ & $\begin{array}{c}\text { Students } \\
(\mathbf{\%})\end{array}$ & & $\begin{array}{c}\text { Facilitators } \\
(\mathbf{\%})\end{array}$ & $\begin{array}{c}\text { Colleagues } \\
\mathbf{( \% )}\end{array}$ & $\begin{array}{c}\text { Students } \\
(\mathbf{\%})\end{array}$ \\
\hline Phone calls & $25(44.6)$ & $31(55.4)$ & & $25(44.6)$ & $22(39.3)$ & $24(42.9)$ \\
SMSs & $15(26.8)$ & $26(46.4)$ & & $14(25.0)$ & $22(39.3)$ & $17(30.4)$ \\
Emails & $9(16.1)$ & $6(10.7)$ & & $8(14.3)$ & $8(14.3)$ & $10(17.9)$ \\
Facebook & $3(5.4)$ & $3(5.4)$ & & $3(5.4)$ & $4(7.1)$ & $4(7.1)$ \\
WhatsApp & $6(10.7)$ & $9(16.1)$ & & $7(12.5)$ & $8(14.3)$ & $6(10.7)$ \\
\hline
\end{tabular}

reported using them at least several times a week. Though 31 (55.4\%) thought mobile phones were important for workrelated clinical care, mobile phones were seldom used to document or share cases by means of images $(n=11 ; 19.6 \%)$.

The most frequent activity reported by respondents was contacting fellow students by phone call $(n=31 ; 55.4 \%)$ followed by SMS messages $(n=26 ; 46.4 \%)$ to discuss study issues. Nearly half $(n=25 ; 44.6 \%)$ used phone calls to contact facilitators for both study and work-related reasons (Table 2).

Social networks: Facebook: The use of Facebook as a social network application on either mobile phone or computer was specifically evaluated as a potential new application to use for educational activities. Regarding the current use of Facebook at the time of the survey, 17 respondents (30.4\%) reported accessing social network sites, such as Facebook, using their laptops and 20 respondents (35.7\%) reported accessing social networks using their smartphones. Twentythree respondents $(41.1 \%)$ agreed that social networking sites were becoming important. However, the use of social networks to reflect on work-related experiences was low with only $10(17.9 \%)$ respondents who reported that they were using social networking sites for that purpose. Obtaining information for medical and clinical support was even lower with only small numbers of respondents using Facebook at least several times a week: for example reading messages from Facebook friends on medical and clinical topics $(n=7 ; 12.5 \%)$, sharing or accessing medical and clinical resource lines in chats $(n=6 ; 10.7 \%)$, as well as sharing medical experiences in chats $(n=5 ; 8.9 \%)$, comments $(n=4 ; 7.1 \%)$, participation in quizzes $(n=2 ; 3.6 \%)$, clinical case presentations $(n=2 ; 3.6 \%)$, and posts $(n=2 ; 3.6 \%)$.

\section{Possibilities for mobile phone and social networking use in the education of midwives in rural communities}

The respondents' perceptions of the use of technology were examined with regard to the potential of using mobile phones and social networking activities such as Facebook to provide access to information and support learning. The characteristics of the institution (educational learning environment and ICT support) were also examined.

\section{Institutional learning environment characteristics}

Teaching related activities: In respect of the potential to enhance the current learning environment using mobile 
TABLE 3: Institutional environment $(N=56)$.

\begin{tabular}{|c|c|}
\hline Variable & Agreement (\%) \\
\hline \multicolumn{2}{|l|}{ Teaching activities } \\
\hline Lecturers include teamwork & $45(80.4)$ \\
\hline Independent problem solving is encouraged & $45(80.4)$ \\
\hline Lecturers engage students in discussions & $41(73.2)$ \\
\hline Lectures consist of formal presentations & $36(64.3)$ \\
\hline Lecturers provide feedback about individual performance & $36(64.3)$ \\
\hline \multicolumn{2}{|l|}{ Facilitators used the following ICTs } \\
\hline Photo camera & $22(39.3)$ \\
\hline Desktop computer & $24(42.9)$ \\
\hline Mobile phone & $31(55.4)$ \\
\hline Video camera & $32(57.1)$ \\
\hline Smartphone & $39(69.6)$ \\
\hline E-learning sites \& course websites & $39(69.6)$ \\
\hline Learning Management Systems & $47(83.9)$ \\
\hline Laptop & $47(83.9)$ \\
\hline \multicolumn{2}{|c|}{ ICT support at the institution for mobile phones and social network sites } \\
\hline The university supports the use of mobile phones for learning & $34(60.7)$ \\
\hline $\begin{array}{l}\text { The university supports the use of social networking sites for } \\
\text { learning }\end{array}$ & $22(39.3)$ \\
\hline $\begin{array}{l}\text { The use of social network sites for educational purposes is being } \\
\text { taught as part of nursing education }\end{array}$ & $17(30.4)$ \\
\hline $\begin{array}{l}\text { The use of mobile devices for educational use is being taught as } \\
\text { part of nursing education }\end{array}$ & $14(25.0)$ \\
\hline \multicolumn{2}{|l|}{ ICT support at work for mobile phones and social networking sites } \\
\hline $\begin{array}{l}\text { The use of mobile devices for educational use is supported } \\
\text { at work }\end{array}$ & $14(25.0)$ \\
\hline $\begin{array}{l}\text { The use of social networking sites for educational use is } \\
\text { supported at work }\end{array}$ & $9(16.1)$ \\
\hline
\end{tabular}

technology, the most prevalent learning activities in respondents' educational programme were teamwork and problem solving ( $n=45,80.4 \%$ ), which were identified as activities that could be enhanced through access and use of ICTs (Table 3 ).

Respondents were asked to identify which ICT facilitators should be used more frequently, with the highest support indicated being for texting ( $n=32 ; 57.1 \%)$, followed by phone calls $(n=30 ; 53.6 \%)$, MS PowerPoint presentations ( $n=27 ; 48.2 \%)$, learning management systems $(n=23$; $41.1 \%)$, e-learning programmes $(n=18 ; 32.1 \%)$, WhatsApp and emailing $(n=14 ; 25.0 \%)$, MS Word documents ( $n=13$; $23.2 \%)$, eBooks $(n=13 ; 23.2 \%)$, video sharing sites $(n=12$; $21.4 \%)$, Skype $(n=11 ; 19.6 \%)$, bookmarking on an Internet browser $(n=10 ; 17.9 \%)$, Internet chats $(n=9 ; 16.1 \%)$, wikis and virtual worlds $(n=6 ; 10.7 \%)$, Facebook $(n=5 ; 8.9 \%)$, podcasts $(n=4 ; 7.1 \%)$, and blogs $(n=3 ; 5.4 \%)$. This was further supported with respondents reporting low use by lecturers of ICTs such as mobile phones $(n=31 ; 55.4 \%)$ (Table 3 ).

Institutional support: Respondents were asked about the ICT support they were receiving for using mobile phones and applications, such as Facebook at work and at institutions for educational purposes. Support for the use of mobile phones and social networking sites at university and work places was generally reported as poor, ranging from 9 (16.1\%) for social networking to $34(60.7 \%)$ for mobile phone support (Table 3). When examining whether mobile phones or social networking sites were used for educational and work-related purposes, more than half of the respondents $(n=32 ; 57.1 \%$ and
TABLE 4: Individual characteristics $(N=56)$

\begin{tabular}{lc}
\hline Variable & Agree (\%) \\
\hline Perceived competency & \\
Competent in the use of a mobile phone & $30(71.4)$ \\
Competent in the use of a smartphone to access the Internet & $34(60.7)$ \\
Competent in the use of a desktop computer/laptop to access & \\
the Internet & $26(46.4)$ \\
Generally competent in the use of a desktop computer/laptop & - \\
Perceived effectiveness of ICTs & $43(76.8)$ \\
Laptop & $41(73.2)$ \\
LMS (e.g. Moodle) & $34(60.7)$ \\
E-learning & $34(60.7)$ \\
Course related websites & $31(55.4)$ \\
Smartphone & $26(46.4)$ \\
Video & $22(39.3)$ \\
Mobile phone & $20(35.7)$ \\
Desktop computer & $17(30.4)$ \\
Camera &
\end{tabular}

$n=34 ; 60.7 \%$ respectively) reported that those functionalities were not supported at work.

\section{Individual characteristics}

There is evidence (Gagnon et al. 2012) that the following individual characteristics are good indicators of future use of technology: perceived levels of competency, perceived effectiveness of technology, and general attitudes towards the use of ICTs.

Perceived competency: The ICT device that the respondents were most competent with was the mobile phone (Table 4). This finding was supported by additional findings that only $23(41.1 \%)$ of the respondents reported that their friends would describe them as interested in the latest technology, and only $30(53.6 \%)$ reported that they found technology easy to use.

Perceived effectiveness of ICTs: In contrast, when respondents were asked to rate the perceived effectiveness of various technologies for learning, most respondents agreed that the laptop was effective $(n=43 ; 76.8 \%)$ followed by an LMS ( $n=41 ; 73.2 \%)$, whilst less respondents agreed that the smartphone $(n=31 ; 55.4 \%)$ and mobile phone $(n=22 ; 39.3 \%)$ were effective (Table 4$)$.

Attitudes: Respondents' attitudes towards the use of ICTs in education were measured with regard to their own learning, their attitudes towards the use of ICTs at the university, and their perceived use of ICTs by their facilitators. The respondents' attitudes towards using ICTs for learning showed that most respondents felt technological devices could be very helpful to access information ( $n=42 ; 75.0 \%$ agreed) but less than half $(n=25 ; 44.6 \%)$ still felt that using technological devices was more helpful than frustrating (Table 5). Regarding the use of technology by the university and the facilitators, the respondents felt that technology was essential for learning $(n=41 ; 73.2 \%)$ and that the university used technology 
TABLE 5: Attitudes towards the use of technology and education $(N=56)$.

\begin{tabular}{|c|c|}
\hline Variable & Agree (\%) \\
\hline \multicolumn{2}{|l|}{ Beliefs about technology and learning } \\
\hline $\begin{array}{l}\text { Information technology has changed the way midwives access } \\
\text { information }\end{array}$ & $44(78.6)$ \\
\hline $\begin{array}{l}\text { Information technology assists me with looking up information } \\
\text { independently }\end{array}$ & $42(75.0)$ \\
\hline $\begin{array}{l}\text { Information technology assists me with verifying information from } \\
\text { lecturers }\end{array}$ & $41(73.2)$ \\
\hline Technology is essential for successful learning & $41(73.2)$ \\
\hline I consider the trustworthiness of information I find on the Internet & $40(71.4)$ \\
\hline Technology is more helpful than frustrating & $25(44.6)$ \\
\hline \multicolumn{2}{|l|}{ Beliefs about technology at the institution } \\
\hline Technology makes facilitators better at their job & $43(76.8)$ \\
\hline Technology is essential for successful teaching & $42(75.0)$ \\
\hline The university uses the technology effectively & $36(64.3)$ \\
\hline $\begin{array}{l}\text { The university needs to ensure the availability of more technology } \\
\text { at rural sites }\end{array}$ & $29(51.8)$ \\
\hline Technology is worth the investment & $33(58.9)$ \\
\hline The university needs more technology & $33(58.9)$ \\
\hline \multicolumn{2}{|l|}{ Beliefs about instructors and technology } \\
\hline My facilitators use technology effectively & $45(80.4)$ \\
\hline My facilitators use technology frequently enough & $43(76.8)$ \\
\hline My facilitators know how to use the technology that is available & $28(50.0)$ \\
\hline \multicolumn{2}{|l|}{ Beliefs about technology (mobile phones) } \\
\hline $\begin{array}{l}\text { Importance of using a mobile phone to discuss educational topics } \\
\text { with facilitators }\end{array}$ & $46(82.1)$ \\
\hline $\begin{array}{l}\text { Importance of using a mobile phone to discuss work-related topics } \\
\text { with facilitators }\end{array}$ & $46(82.1)$ \\
\hline Importance of mobile phones to search for work-related information & $43(76.8)$ \\
\hline $\begin{array}{l}\text { Importance of using a mobile phone to discuss work-related topics } \\
\text { with students }\end{array}$ & $41(73.2)$ \\
\hline $\begin{array}{l}\text { Importance of using a mobile phone to discuss work-related topics } \\
\text { with colleagues }\end{array}$ & $39(69.6)$ \\
\hline Mobile phones have changed the way I learn & $35(62.5)$ \\
\hline Mobile phones are important tools in my daily life & $30(53.6)$ \\
\hline \multicolumn{2}{|l|}{ Beliefs about technology (Facebook) } \\
\hline Social networking sites have changed the way I learn & $35(62.5)$ \\
\hline Using Facebook for medical topics supports my learning & $13(23.2)$ \\
\hline
\end{tabular}

appropriately ( $n=36 ; 64.3 \%$ ). However, more investment was needed ( $n=33 ; 58.9 \%)$ and although facilitators used technology effectively $(n=45 ; 80.4 \%)$ and frequently ( $n=43 ; 76.8 \%$ ), they did not know how to use technology that was available $(n=28 ; 50.0 \%)$ (Table 5).

The respondents' attitudes towards the possible future use of mobile phones and Facebook for educational purposes were measured (Table 4). Though only half the respondents viewed mobile phones as important in their daily lives, mobile phones were rated important with regard to discussing learning and accessing information $(n=44$; $78.6 \%$ ). Respondents were positive about the use of social networking sites to assist their education ( $n=31 ; 55.4 \%)$, however the specific ratings for Facebook were poor; only 13 respondents (23.2\%) reported that they were using Facebook for obtaining medical information (Table 5).

\section{Discussion}

In the context of using mobile phones and social networks to provide access to educational learning opportunities in lowly resourced settings for nurses, the following factors were considered: the specific rural context, the learners, and the potential applications and perceptions of these technologies for learning purposes.

Owing to insufficient access to the Internet at homes in the rural areas, mobile phones provide an opportunity to increase access to the Internet for learners. In South Africa mobile phones offer access to the Internet more readily than fixed line Internet connections at home, specifically in rural households where $17.9 \%$ of rural households access the Internet by using mobile devices as opposed to home Internet connection (2\%) (Statistics South Africa 2013). In our study, a similar pattern was confirmed with low personal computer ownership. Unfortunately, rural hospitals in KwaZulu-Natal had very limited Internet access with a very slow bandwidth of $148 \mathrm{kbps}$ (Wooton et al. 2009). In contrast, all except two respondents in this study reported that they owned a mobile phone. Half of them specifically reported owning smartphones that were used to access the Internet.

A second issue concerns the characteristics of nursing learners resident in rural areas, specifically regarding age and attitude towards the use of new technology. Owing to the fact that the respondents in this study were already qualified professional nurses, they were older learners with an average age over 40 years with $16 \%$ of the respondents over the age of 50 years. This finding was similar to the findings of other studies conducted in nursing at these settings (Chipps et al. 2015). Older nurses (nurses with extensive experience) might be more reluctant to embrace new technologies (Putzer \& Park 2010), and age is known to be a factor that significantly affects computer competency levels (Hsu et al. 2009). Our study supported these findings, with more than half the respondents who reported low levels of computer competency and difficulty in using new technology. Generally, however, respondents felt relatively competent in using their mobile phones, though less so with new technological tools such as Facebook, with less than half of them ever having used Facebook. Only one of the Facebook users was over 50 years old.

Attitudes towards using a smartphone and technology are reported to have influenced the intention to use technology such as a smartphone (Chen, Park \& Putzer 2010; Gagnon et al. 2012; Putzer \& Park 2010). Generally, the respondents had a positive attitude towards technology and investments in technology by universities and their work place, though their views in respect of the use of those technologies for educational purposes remained out of date. Most of them rated the laptop as the most effective ICT for education and learning, followed by learning management systems and smartphones.

In assessing the potential for using mobile phones and social networks for learning at the time of the study, respondents' mobile phone usage patterns, specific views on the use of mobile phones and social networks for education purposes, and institutional support were examined. The use of mobile phones and smartphones is increasing in health care provision with $64 \%$ of American physicians in 2009 using smartphones 
(Gill, Kamath \& Gill 2012) and more than three-quarters of nurses in a recent study acknowledging that they often use their personal mobile phone or other communication devices at work, excluding during breaks or meal times (McBride, LeVasseur \& Li 2015). The respondents in our study reported higher use of mobile phones compared to any of the other ICTs for educational and work-related activities, including contacting facilitators or peers to discuss topics and tasks related to the programme or work and searching for information. Making phone calls was the most frequent activity followed by SMS or texting, but they reported low current usage of smartphone functions.

With reference to social networks, the low engagement on Facebook in our study contradicts international studies of younger nurses with reports in the USA of up to $90 \%$ engagement on Facebook (Ferguson 2013). This is viewed as being related to the age of the nurses. Although, similar to international studies (Ferguson 2013; Schmitt, SimsGiddens \& Booth 2012) the respondents reported that social networking sites such as Facebook were becoming important in the nursing profession and education, regular use in our study to reflect on work-related experiences was low. Mobile phones were rated as important with regard to discussing learning and accessing information, and respondents were positive about the use of social networking sites to augment their education. However, the specific ratings for Facebook were poor. This could possibly be due to a perception that mobile phones and Facebook are not used for educational and clinical purposes and concerns about the potential distraction of those devices in a working environment (McBride et al. 2015).

Numerous studies have found that adoption of new technologies is largely dependent on the internal support of organisations (Bhattacherjee \& Hikmet 2008; Putzer \& Park 2010). The positive views towards potential use of mobile phones for learning were in direct opposition to reported poor support for the use of social networks or mobile phones at university or work. This was further compounded by a perception of lecturers' poor awareness of the latest technology available for education and learning.

\section{Limitations}

The study had a number of limitations. The main limitation was the $50 \%$ response rate which might have influenced the findings as a result of the non-responders' own disposition towards using ICTs. Likewise, there was uncertainty about whether the respondents clearly understood the dissimilarity between mobile phones with smartphone capacities and traditional mobile phones.

\section{Recommendations}

A number of recommendations emerged from this study. Firstly, there is empirical evidence from studies that the potential exists to use mobile phones and social networks more systematically in lowly resourced settings to facilitate nursing education. Institutions should evaluate how mobile phones and social media can contribute to key aspects of education, how to integrate them, and how to support learners to use them effectively. Specifically, orientation and training of older learners should be done to raise their awareness and skills in using mobile and social networks. Nursing education should invest in developing guidelines for the use of mobile phones in the clinical settings (Royal College of Nursing 2012). However, more formal research into possible strategies and interventions to facilitate the uptake of technologies in education in these setting is recommended.

\section{Conclusion}

The study revealed an inherent tension and struggle between respondents' relatively high usage patterns of mobile phones and high expectations with regard to their value for learning and work purposes on the one hand, and their limited perceived technical competency and the restricted institutional support on the other. Thus, it is concluded that much would be gained when educational institutions start supporting the learners with the use of mobile phones more systematically, particularly concerning the development of mobile literacy skills.

\section{Acknowledgements Competing interests}

The authors declare that they have no financial or personal relationship(s) that may have inappropriately influenced them in writing this article.

\section{Authors' contributions}

All authors help with the conceptualisation of the study and review of this article. F.W. (University of KwaZulu-Natal) and T.N. (University of KwaZulu-Natal) did the data collection. C.P. (University of Applied Sciences and Arts North-western Switzerland) did the literature review and J.C. (University of the Western Cape) the data analysis and preparation of the article for publication.

\section{References}

Bhattacherjee, A. \& Hikmet, N., 2008, 'Reconceptualizing organizational support and its effect on information technology usage: Evidence from the health care sector', Journal of Computer Information Systems 48, 69-76.

Braun, R., Catalani, C., Wimbush, J. \& Israelski, D., 2013, 'Community health workers and mobile technology: A systematic review of the literature', PLoS One 8, e65772. http://dx.doi.org/10.1371/journal.pone.0065772

Chang, A.Y., Ghose, S., Littman-Quinn, R., Anolik, R.B., Kyer, A., Mazhani, L. et al., 2011, 'Use of mobile learning by resident physicians in Botswana', Telemedicine and - $-H E A L T H$.

Chen, J., Park, Y. \& Putzer, G.J., 2010, 'An examination of the components that increase acceptance of smartphones among healthcare professionals', Electronic Journal for Health Informatics 5.

Chib, A., 2013, 'The promise and peril of mhealth in developing countries', Mobile Media \& Communication 1, 69-75. http://dx.doi.org/10.1177/2050157912459502

Chib, A. \& Chen, V.H.-H., 2011, 'Midwives with mobiles: A dialectical perspective on gender arising from technology introduction in rural Indonesia', New Media \& Society 13, 486-501. http://dx.doi.org/10.1177/1461444810393902 
Chib, A., Van Velthoven, M.H. \& Car, J., 2014, 'mHealth adoption in low-resource environments: A review of the use of mobile healthcare in developing countries', environments: A review of the use of mal
Journal of Health Communication 1-53.

Chipps, J., Kerr, J., Brysiewicz, P. \& Walters, F., 2015, 'A survey of University students' perceptions of learning management systems in a low-resource setting using a technology acceptance model', Computers, Informatics, Nursing 33, 71-77. technology acceptance model', Computers, Inform

Clay, C.A., 2011, 'Exploring the use of mobile technologies for the acquisition of clinical skills', Nurse Educ Today 31, 582-586. http://dx.doi.org/10.1016/j. nedt.2010.10.011

Crow, J., Broussard, R., Dong, L., Finn, J., Wiley, B. \& Geisler, G., 2012, 'A synthesis of research on ICT adoption and use by medical professionals in Sub-Saharan Africa', Proceedings of the 2nd ACM SIGHIT International Health Informatics Symposium, 2012, ACM, pp. 161-170. http://dx.doi.org/10.1145/2110363.2110384

De Marcos Ortega, L., Barchino Plata, R., Jimenez Rodriguez, M.L., Hilera Gonzalez, J.R., Martinez Herraiz, J.J., Gutierrez De Mesa, J.A. et al., 2011, 'Using m-Learning on nursing courses to improve learning', Computers, Informatics, Nursing 29, 311317. http://dx.doi.org/10.1097/NCN.0b013e3181fcbddb

Deglise, C., Suggs, L.S. \& Odermatt, P., 2012, 'Short message service (SMS) applications for disease prevention in developing countries', Journal of Medical Internet Research 14, e3. http://dx.doi.org/10.2196/jmir.1823

Educause, 2011, ECAR national study of undergraduate students and information technology, viewed 10 March 2015, from http://www.educause.edu/library/ resources/ecar-national-study-undergraduate-students-and-informationtechnology-2011-report

Favell, A., 2010, Mobile social networking - the statistics are compelling, viewed 19 August 2013, from http://mobiforge.com/research-analysis/mobile-socialnetworking-statistics-are-compelling?mT

Ferguson, C., 2013, 'It's time for the nursing profession to leverage social media' Journal of Advanced Nursing 69, 745-747. http://dx.doi.org/10.1111/ jan.12036

Gagnon, M.-P., Légaré, F., Desmartis, M., Labrecque, M., Car, J., Pagliari, C. et al., 2012 , 'Systematic review of factors influencing the adoption of information and communication technologies by healthcare professionals', Journal of Medical Systems 36, 241-277. http://dx.doi.org/10.1007/s10916-010-9473-4

Gill, P.S., Kamath, A. \& Gill, T.S., 2012, 'Distraction: An assessment of smartphone usage in health care work settings', Risk Management and Healthcare Policy 5, 105-114. http://dx.doi.org/10.2147/RMHP.S34813

Gray, K., Annabell, L. \& Kennedy, G., 2010, 'Medical students' use of Facebook to support learning: Insights from four case studies', Medical Teacher 32, 971-976. http://dx.doi.org/10.3109/0142159X.2010.497826

Havelka, S., 2011, 'Mobile resources for nursing students and nursing faculty', Journa of Electronic Resources in Medical Libraries 8, 194-199. http://dx.doi.org/10.1080/ 15424065.2011.576623

Hifa Report, 2010, Healthcare information for all by 2015. Annual review 2010 Charlbury Oxford, viewed 15 January 2012, from http://www.hif2015.org

Holmes, D., 2010, 'Rwanda: An injection of hope', The Lancet 376, 945-946. http:// dx.doi.org/10.1016/S0140-6736(10)61436-5

Hongoro, C. \& Mcpake, B., 2004, 'How to bridge the gap in human resources for health', The Lancet 364, 1451-1456. http://dx.doi.org/10.1016/S0140-6736(04)17229-2

Hsu, H.-M., Hou, Y.-H., Chang, I.C. \& Yen, D., 2009, 'Factors influencing computer literacy of Taiwan and South Korea nurses', Journal of Medical Systems 33, 133-139. http://dx.doi.org/10.1007/s10916-008-9173-5

Hwang, G.J. \& Tsai, C.C., 2011, 'Research trends in mobile and ubiquitous learning: A review of publications in selected journals from 2001 to 2010', British Journa of Educational Technology 42, E65-E70. http://dx.doi.org/10.1111/j.14678535.2011.01183.x

Itu, 2010, Barcelona: International telecommunication union, Media Release, viewed 09 October 2010, from http://www.itu.int/net/pressoffice/press releases/2010/06.aspx

Itu, 2014, Measuring the information society: Report, viewed 1 January 2015, from http://www.itu.int/en/ITU-D/Statistics/Documents/publications/mis2014/ MIS2014_without_Annex_4.pdf

Kolko, B.E., Rose, E.J. \& Johnson, E.J., 2007, 'Communication as information-seeking: The case for mobile social software for developing regions', 16th International Conference on World Wide Web, 2007, New York, ACM, pp. 863-872. http:// dx.doi.org/10.1145/1242572.1242689

Lee, S., Chib, A. \& Kim, J.-N., 2011, 'Midwives' cell phone use and health knowledge in rural communities', Journal of Health Communication 16, 1006-1023. http:// dx.doi.org/10.1080/10810730.2011.571344
McBride, D.L., Levasseur, S.A. \& Li, D., 2015, 'Non-work-related use of personal mobile phones by hospital registered nurses', JMIR Mhealth Uhealth 3, e3. http://dx.doi. org/10.2196/mhealth.4001

McLeod, R.P. \& Mays, M.Z., 2008, 'Back to the future: Personal digital assistants in nursing education', Nursing Clinics of North America 43, 583-592, vii. http:// dx.doi.org/10.1016/j.cnur.2008.06.008

Mechael, P., Batavia, H., Kaonga, N., Searle, S., Kwan, A., Goldberger, A. et al., 2010 Barriers and gaps affecting $\mathrm{m}$-Health in low and middle income countries. Policy white paper, Center for Global Health and Economic Development, Earth Institute, Columbia University, New York, NY, viewed on 31 October 2014, from http://cgsd. columbia.edu/files/2012/11/mHealthBarriersWhitePaperFINAL.pdf

Phillippi, J.C. \& Wyatt, T.H., 2011, 'Smartphones in nursing education', Computers, Informatics, Nursing 29, 449-454. http://dx.doi.org/10.1097/NCN.0b013e3181 fc411f

Pimmer, C., Brysiewicz, P., Linxen, S., Walters, F., Chipps, J. \& Gröhbiel, U., 2014, 'Informal mobile learning in nurse education and practice in remote areas. A case study from rural South Africa', Nurse Education Today 34, 1398-1404. http:// dx.doi.org/10.1016/j.nedt.2014.03.013

Pimmer, C., Linxen, S. \& Gröhbiel, U., 2012a, 'Facebook as a learning tool? A case study on the appropriation of social network sites along with mobile phones in developing countries', British Journal of Educational Technology 43, 726-738. http://dx.doi.org/10.1111/j.1467-8535.2012.01351.x

Pimmer, C., Linxen, S. \& Gröhbiel, U., 2012b, 'Facebook as a learning tool? A case study on the appropriation of social network sites from mobile phones in developing countries', British Journal of Educational Technology 43, 726-738. http://dx.doi. org/10.1111/j.1467-8535.2012.01351.x

Pimmer, C., Linxen, S., Gröhbiel, U., Jha, A. \& Burg, G., 2013, 'Mobile learning in resource-constrained environments. A case study of medical education', Medical Teacher 35, e1157-e1165. http://dx.doi.org/10.3109/0142159X.2012.733454

Putzer, G.J. \& Park, Y., 2010, 'The effects of innovation factors on smartphone adoption among nurses in community hospitals', Perspectives in Health Information Management / AHIMA, American Health Information Management Association 7, 1b.

Royal College of Nursing, 2012, RCN guidance. Nursing staff using personal mobile phones for work purposes, Royal College of Nursing, London.

Schmitt, T., Sims-Giddens, S. \& Booth, R., 2012, 'Social media use in nursing education', OJIN: The Online Journal of Issues in Nursing 17, Manuscript 2.

Statistics South Africa, 2013, General household survey, Statistics South Africa, Pretoria.

The World Bank, 2011, The little data book on information and communication technology, International Bank for Reconstruction and Development, Washington, viewed 16 August 2011, from http://eurasiapac-fp7.eu/files/2011/07/ICT11_ Version7.pdf

The World Bank, 2012, Information and communications for development Maximizing mobile, Washington, DC, viewed 29 September 2012, from http:// www.worldbank.org/ict/IC4D2012

Tomlinson, M., Rotheram-Borus, M.J., Swartz, L. \& Tsai, A.C., 2013, 'Scaling up mHealth: Where is the evidence?', PLoS Medicine, viewed 03 June 2013, from http://www. Where is the evidence?', PLOS Medicine, viewed 03 June 2013, from http://wW
plosmedicine.org/article/info\%3Adoi\%2F10.1371\%2Fjournal.pmed.1001382

Traxler, J., 2012, 'The challenge of working across contexts and domains: Mobile health education in rural Cambodia', in A. Chib \& R. Harris (eds.), Linking research to practice in Asia: ICT for development research, management and perspectives, to practice in

Traxler, J. \& Kukulska-Hulme, A., 2005, Mobile learning in developing countries, Commonwealth of Learning, viewed 03 January 2012, from http://dspace.col.org/ bitstream/123456789/159/1/KS2005_mlearn.pdf

WHO, 2010, Increasing access to health workers in remote and rural areas through improved retention. Global policy recommendations, viewed n.d., from http:// www.who.int/hrh/retention/guidelines/en/index.html

Winters, N., 2013, 'Mobile learning in the majority world: A critique of the GSMA position', in S. Price, C. Jewitt \& B. Brown (eds.), The SAGE handbook of digital technology research. http://dx.doi.org/10.4135/9781446282229.n27

Wooton, R., Patil, N.G., Scott, R.E. \& Ho, K., 2009, Telehealth in the developing world, Royal College of Medicine Press Ltd, London.

Wu, W.H., Jim Wu, Y.C., Chen, C.Y., Kao, H.Y., Lin, C.H. \& Huang, S.H, 2012, 'Review of trends from mobile learning studies: A meta-analysis', Computers \& Education 59, 817-827. http://dx.doi.org/10.1016/j.compedu.2012.03.016

Young, P., Moore, E., Griffiths, G., Raine, R., Stewart, R., Cownie, M. et al., 2010, 'Help is just a text away: The use of short message service texting to provide an additional means of support for health care students during practice placements', Nurse means of support for health care students during practice placements', $N$
Education Today $30,118-123$. http://dx.doi.org/10.1016/j.nedt.2009.06.010 